\title{
Identicifation of Hookworm Species in Stool By Harada Mori Culture
}

\author{
Shahid SB ${ }^{1}$, Wazib A ${ }^{2}$, Chowdhury A ${ }^{1}$, Shamsuzzaman SM ${ }^{3}$, Mamun KZ ${ }^{4}$ \\ ${ }^{1}$ Lecturer, Dept. of Microbiology, Dhaka Medical College, Dhaka; ${ }^{2}$ Clinical Pathologist, Dept. of Microbiology, Dhaka Medical \\ College, Dhaka; ${ }^{3}$ Associate Professor, Dept. of Microbiology, Dhaka Medical College, Dhaka; ${ }^{4}$ Professor and Head, Dept. of \\ Microbiology, Dhaka Medical College, Dhaka.
}

\begin{abstract}
This cross sectional study was done from January 2009 to June 2010 in Microbiology department of Dhaka Medical College, Dhaka to identify hookworm species and to compare different laboratory methods for diagnosis of hookworm infections. Among the 375 stool samples evaluated, 26 (6.93\%) samples were positive for hookworms. Ankylostoma duodenale were $3(11.50 \%)$ and Necator americanus were $23(88.50 \%)$. Harada Mori culture was found as the most effective method for detection of hookworms.
\end{abstract}

Key words: Hookworm; Harada Mori culture.

\section{Introduction}

Intestinal parasitic infections are globally endemic and have been described as constituting the greatest single worldwide cause of illness and disease. ${ }^{1}$ The World Health Organization (WHO) estimates that 3.5 billion people worldwide are infested with some type of intestinal parasite, and as many as 450 million of them are sick as a result. ${ }^{2}$ Ascaris lumbricoides, Trichuris trichiura and hookworms, collectively referred to as soil-transmitted helminths (STHs), are the most common intestinal nematodes. ${ }^{3}$ Direct stool smear technique is quick to prepare and inexpensive when compared with other methods but it can miss eggs of hookowrms if concentration is too low or if too much debris or fat is present. ${ }^{4}$ There is need for increase probability of finding the parasite in the fecal samples to allow for accurate diagnosis, hence there is need to practice other methods. ${ }^{5}$ It has been proved that Harada Mori culture technique offers many advantages over direct stool smear technique for detecting hookworms. If performed correctly, this methods is sensitive, simple, economical and ease to carry out. $5,6,7$

\section{Material and Methods}

This cross sectional study included 375 person of all age group of the patients attending at outpatient department of

\section{Correspondence:}

Dr. Sazzad Bin Shahid

Lecturer, Department of Microbiology

Dhaka Medical College, Dhaka- 1000.

E-mail: sazzadshahid@gmail.com.
Dhaka Medical College, people of two villages Konakhola and Malancha in Keraniganj Upazilla, Dhaka, children from an orphanage in Dhaka city and among people of two urban slum Korail and Kamrangirchar in Dhaka city. The sample was selected by simple random sampling. After labeling, a plastic container was supplied to each person to collect the stool in the next morning. The container of stool samples was collected during visit in the next morning and was transported to the microbiology laboratory as early as possible. The collected stool was immediately examined macroscopically and microscopically and was cultured by Harada Mori culture technique. ${ }^{7}$ The results of the study were recorded systematically. Data analysis was done manually.

\section{Result}

A total of 375 stool samples from healthy people of different age and sex were included in this study. Most $(45.06 \%)$ were in the age group of 10 years. Highest prevalence (61.53\%) of hookworm infections were in the age group of 10 years (Table I).

Table I: Distribution of parasite infections in different age groups.

\begin{tabular}{ccc}
\hline Age in years & Number examined & Number infected \\
\hline 5 & 78 & 6 \\
$6-10$ & 91 & 10 \\
$11-20$ & 58 & 5 \\
$21-30$ & 42 & 2 \\
$31-40$ & 47 & 1 \\
$41-50$ & 34 & 1 \\
$>50$ & 25 & 1 \\
Total & 375 & 26 \\
\hline
\end{tabular}


Among the 26 Harada Mori culture positive stool samples, only $3(11.53 \%)$ were detected as $A$. duodenale and 23 $(88.47 \%)$ were detected as $N$. americanus.

Different methods of stool examination are compared in Table-II.

Table II: Detection of hookworms by different procedures.

\begin{tabular}{|c|c|c|c|c|}
\hline \multicolumn{2}{|c|}{ Routine microscopy } & & Formal petrol & Harada \\
\hline Saline & Iodine & method & & \\
\hline 15 & 12 & 04 & 05 & 26 \\
\hline
\end{tabular}

\section{Discussion}

In this study, among the 375 samples, 26 (10.15\%) were infected by hookworm. Among the 26 infections, 17 $(65.39 \%)$ were found in two villages of Keraniganj Upazilla and $9(34.61 \%)$ were found in two slums of Dhaka city. Hookworm was more prevalent in rural areas. This is due to people of these two villages mostly walk barefooted. In contrast, the prevalence was much lower in the study population in and around Dhaka city where most of the people live in urban setting and most of them use foot wear. A study in Dhaka by Muscat et al. (2004) had shown that the prevalence of hookworm was $10 \%$ which is similar to the present study. Similar low prevalence (07.9\%) was also observed by Huq and Yasmin (1985) in Dhaka city. In contrast, study on intestinal parasite among tea gardeners in Sylhet by Ali et al. (1985) showed the prevalence of hookworm was $28.4 \%$ which is higher than present study and this higher prevalence might be due to most of the most people in tea garden walk barefooted and the moist soil of tea garden facilitates the survival and maturation of hookworm larvae. This study showed that $N$. americanus was the dominant hookworm species $(88.47 \%)$ in the study population. Huq and Yasmin (1985) found the prevalence of $N$. americanus was $68 \%$ among the hookworm infection.

Among 26 Harada Mori culture positive cases of stool samples, 15(57.69\%) were positive in routine microscopic examination. This reflects that hookworm eggs might be missed during wet film microscopy but can be detected by Harada Mori culture method. This might be due to the fragile nature of hookworm eggs which tend to disappear shortly after preparation. But when the sample was placed directly in Harada Mori culture tube there was the growth of hookworm larvae which indicates the patient was infected with hookworm. Similar study by Okolie (2007) in Nigeria showed that Harada Mori culture was more effective to detect hookworm than routine wet film microscopy.
1. Mehraj V, Hatcher J, Akhtar S, Rafique G, Beg MA. Prevalence and factors associated with intestinal parasitic infection among children in an urban slum of Karachi. PLoS ONE. 2008; 3 (11): 1-4.

2. Training manual on diagnosis of Intestinal parasites. Geneva, Switzerland. World Health Organization. 2004; pp. 5-21.

3. Bethony J, Brooker S, Albonico M, Geiger SM, Loukas A, Diemert D, Hotez PJ.Soil-transmitted helminth infections: ascariasis, trichuriasis, and hookworm. The Lancet. 2006; 367: 1521-32.

4. Oguoma V, Ekwunife C. The need for a better method: Comparison of direct smear and formol-ether concentration techniques in diagnosing intestinal parasites. Internet J Trop Med. 2007; 3(2): 1-6.

5. Wirkom V, Tata R, Agba M, Nwobu G, Ndze R, Onoja O, et al. Formol-petrol stool concentration method, a cheap novel technique for detecting intestinal parasites in resource-limited countries. Internet J Trop Med. 2008; 5(1): 1-7.

6. Goodman D, Haji HJ, Bickle QD, Stoltzfus RJ, Tielsch JM, Ramsan M, Savioli L, Albonico M. A comparison of methods for detecting the eggs of Ascaris, Trichuris and hookworm in infant stool, and the epidemiology of infection in Zanzibari infants. Am J Trop Med Hyg. 2007; 76(4): 725-731.

7. Muscat M, Mamun KZ, Tabassum S, Ahmed AA, Shears P. Environmental risk factors and intestinal parasitic carriage in Bangladesh. Journal of Dhaka Medical College. 2004; 13(1): 1-7.

8. Haque R, Ali IM, Petri WA. Prevalence and immune response to Entamoeba histolytica infection in preschool children in Bangladesh. American Journal of Tropical Medicine and Hygiene. 1999; 60(6): 1031-1034.

9. Ali SS, Barbhuyia MAK, Rahman AKM, Chowdhury SA. Incidence of hookworm among the workers in tea garden. Bangladesh Medical Research Council Bulletin. 1985; 11(2): 69-74.

10. Huq F, Yasmin M. Necator americanus and Ankylostoma duodenale in Dhaka city. Bangladesh Medical Research Council Bulletin. 1985; 11(2): 45-50.

11. Okolie NJC. Application of Haradi Mori's culture method for differentiating hookworm species in two major cities of Southern Nigeria. Research Journal of Medical Sciences. 2007: 1(1): 16-20. 